\title{
Applying Back Propagation Neural Networks in the Prediction of Management Associate Work Retention for Small and Medium Enterprises
}

\author{
Kuo-Yan Wang ${ }^{1, *}$, Hsien-Yu Shun ${ }^{2}$ \\ ${ }^{1}$ CHINA-ASEAN International College, Dhurakij Pundit University, Thailand \\ ${ }^{2}$ Shanghai Wei Ming Management Consulting Co., Ltd., China
}

Copyright $\bigcirc 2016$ by authors, all rights reserved. Authors agree that this article remains permanently open access under the terms of the Creative Commons Attribution License 4.0 International License

\begin{abstract}
Since investment in employee education and development represents a significant capital expenditure, the recruitment of employees whose personal characteristics, professional skills and abilities meet the required standards are the important aspect of business management. In small and medium enterprises selecting appropriate individuals to fill management positions represents a significant challenge. This paper focused on an empirical case study utilizing the data of 100 management trainees using back propagation neural networks to determine the probability of retaining management associates. Several surprising results were obtained. Implications for win-win employee-employer relations and practice are discussed.
\end{abstract}

Keywords Employee Education and Development, Employee Retention, Back Propagation Neural Networks, Management Associate

\section{Introduction}

Since Schultz [1] introduced the notion of "human capital" in the early 1960s, enterprises have increasingly emphasized the development of human resources. Over the decades 'personnel affairs' became 'human resources (HR)', and firms began to initiate holistic programs to promote the overall well-being of employees, rather than focusing solely on their work competence. This has inspired a great deal of corresponding discussion on the concept of 'value-creation through employees' among academics. For example, Hurrell and Scholarios [2] investigated the effect of corporate-staff relations on brand values, Ployhart and Moliterno [3] evaluated mechanisms for sharing professional knowledge, experience, judgment, and preferences and Barney et al. [4] and Barney [5] used resource-based theory to describe corporate HR development practices.

The hiring and training of new employees is an important aspect of corporate HR development. The relations between the psychological changes in a new employee, and employee fulfilment and contributions as perceived by the employer is a widely discussed topic in HR [6][7][8][9][10].

Wright and McMahan [11] discussed the difficulties of increasing hired talent in order to produce management associates (MAs). They focused on decreasing the 'trial-and-error cost' of between employee and employer and creating an optimal trade-off between investment in employee training and the retention of effective employees. To ensure the right person is working in the right place, HR management entails not only the initial stage of staff recruitment and professional training, but also subsequent performance screening. For small and medium enterprises (SME) in particular, development of appropriate internal management talent is important, as external recruitment is difficult and the costs of training higher for these smaller sized firms. A lack of effective MAs will hinder long-term development of firms. The existing articles, however, have not deal directly with this problem, particularly because the cost of firm hired and trained MAs is greater than an ordinary staff.

This study applied neural networks, which has been widely used as a prediction tool in the field of HR over the last 20 years [12]. Examples include studies into employee career development [13], hiring and selection [14], and professional attitudes [15]. In view of the considerable body of research regarding human resource management, Strohmeier and Piazza [16] opined that the technique will continue to undergo development. Based on knowledge creation and sharing of 'human affairs' in the workplace, the neural network technique assists decision making process because of it is highly depend on human activities, particular in the learning and thinking process. In other words, learn from the past experiences. This study therefore used neural networks to construct a prediction model of the personal and professional performance of MAs.

The remainder of this paper is organized as follows. The 
next section briefly presents the back propagation (BP) neural network method. Section 3 presents a prediction model, the purpose of which was to determine the probability that the MAs observed in the case study would retain their jobs. It also reveals the preliminary analysis and results. Conclusions are drawn in the final section.

\section{Back Propagation (BP) Neural Network Method}

The BP method is derived from the artificial neural network (ANN) technique developed by Rumelhart et al [17]. The inclusion of BP increases the accuracy of prediction through its consideration of the interaction between inputs and outputs [18]. This makes it a more effective evaluative model than traditional discriminant analysis and multiple logistic regressions.

The BP neural network method comprises three layers: an input layer, a hidden layer, and an output layer. Nodes occur on each of these layers and these nodes are linked by forward and back propagation. This two-way propagation strengthens the indicators. If the desired results are not achieved in the output layer, the network automatically enters back propagation, searching for appropriate weighting values to realize the correct network output.

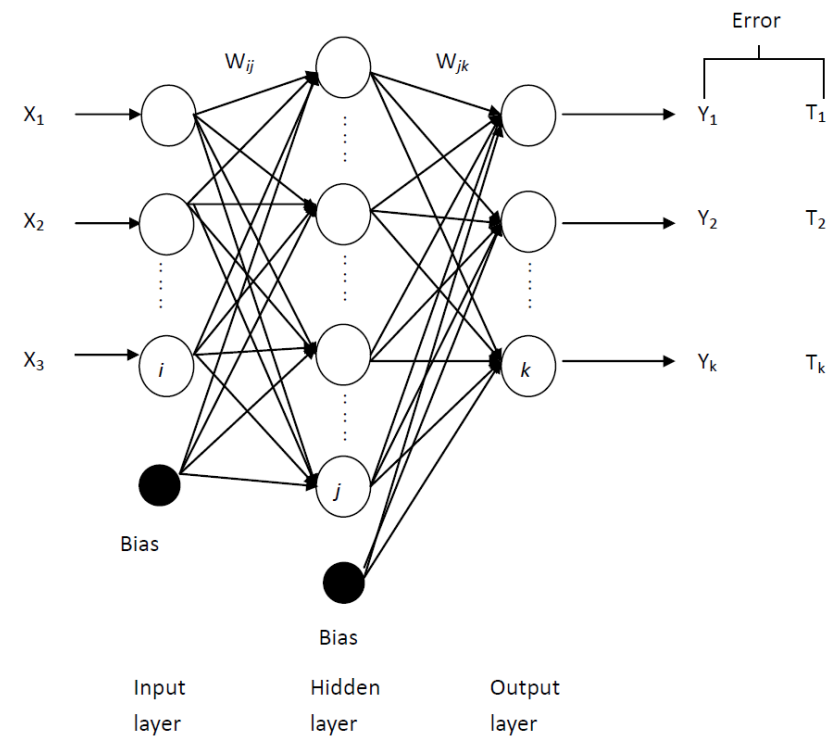

Figure 1. Typical structure of BP neural network

Consider sample set $\mathrm{x}(\mathrm{x}=1,2, \ldots, \mathrm{X})$ and set output $\mathrm{k}(\mathrm{k}=1,2, \ldots, \mathrm{K})$ from output layer $\mathrm{O}_{\mathrm{kx}}$ of a $\mathrm{BP}$ neural network. Assume input layer $\mathrm{w}_{\mathrm{kj}}$ and hidden layer $\mathrm{v}_{\mathrm{ji}}$ are linked due to equivalent weight values. The output function then consists of the hidden layer and output layer and utilizes the bipolar function. The error function $\mathrm{E}$ can be defined as a square function:

$$
E=\frac{1}{2} \sum_{x=1}^{X} \sum_{k=1}^{K}\left(d_{k}-O_{k x}\right)^{2}
$$

where $d_{k}$ denotes the corresponding desired output value.

Learning process is the essential part of the BP neural network, so weight values must be constantly revised in order to shift the error function $\mathrm{E}$ to zero. According to the principle of error gradient decline, the adjustment of $\mathrm{w}_{\mathrm{kj}}$ and $\mathrm{v}_{\mathrm{ji}}$ can be described as follows:

$$
\begin{gathered}
\Delta w_{k j}=-\eta \frac{\partial E}{\partial w_{k j}} \\
\Delta v_{j i}=-\eta^{\prime} \frac{\partial E}{\partial v_{j i}}
\end{gathered}
$$

where $\eta$ and $\eta^{\prime}$ denote the rate of learning.

Amending weight values is an iterative process, that is

$$
\left\{\begin{array}{l}
w_{k j}(n+1)=w_{k j}(n)+\eta \sum_{x=1}^{X} \delta_{k x} O_{j x} \\
V_{j i}(n+1)=v_{j i}(n)+\eta^{\prime} \sum_{x=1}^{X} \delta_{j x} O_{j x}
\end{array}\right\},
$$

In this equation:

$$
\left\{\begin{array}{l}
\delta_{k x}=\left(d_{k}-O_{k x}\right) O_{k x}\left(1-O_{k x}\right) \\
\delta_{j x}=\left(\sum_{k=1}^{K} \delta_{k x} w_{k j}\right) O_{j x}\left(1-O_{j p}\right)
\end{array}\right\}
$$

The procedure of the BP neural network is summarized in the following five steps:

1. Set up the weight value, given a random number e.g. from zero to one.

2. Input raw data with a maximum acceptable error value of the sample which can attempt to meet the expectations of the output layer neural.

3. Compute the real output in each layer.

4. Amend the weight value through back propagation, moving from the output layer to the preceding hidden layer.

5. Repeat Steps 1 to 4 until error function returns a value below that specified in 2 .

\section{An Illustrative Example}

Firm $\mathrm{Y}$ is a leading apparel company with twenty-year experiences and over 1,600 employees. The management found a waning level of performance attributable to their aging workforce. There were no procedures in place to facilitate the training of younger employees. High-level, experienced personnel with engineering and management graduate degrees were required to replace outgoing managers. Firm Y hired 20 professionals and positioned them in the following departments as part of their MA training program: accounting, engineering design, executive assistance, manufacturing, and marketing. 
Firm Y then constructed a knowledge-based system to avoid the human resource gap from re-occurring. To predict the probability of retaining their MAs, the system used 100 management trainees from the past two decades to create the learning process, and took the current 20 MA program participants as the inference sample. During their probationary period, the following characteristics were considered: professional background, adaptation to the new work environment, knowledge sharing, and job performance.

To create a predictive model, two quantitative indicators for job performance were defined: previous working experience, and family status (single/married/married with children). Three qualitative criteria were also introduced, namely professional proficiency, cooperative ability, and work stress tolerance. These were evaluated by an immediate superior using a $1-10$ scale rating $(10=$ extremely satisfied; $1=$ extremely unsatisfied). Table 1 presents the definition of each indicator.

Table 1. Definitions of inputs and outputs for firm Y's MA evaluation

\begin{tabular}{|c|c|c|}
\hline Indicator & Definition & Data type \\
\hline $\begin{array}{c}\text { Previous working } \\
\text { experience }\end{array}$ & $\begin{array}{c}\text { Working years before } \\
\text { report-for-duty of firm } \mathrm{X}\end{array}$ & Continuous \\
\hline Family status & $\begin{array}{c}\text { Single=0; Married=1; } \\
\text { Married with children=2 }\end{array}$ & Discrete \\
\hline $\begin{array}{c}\text { Professional } \\
\text { proficiency }\end{array}$ & $\begin{array}{c}1-10 \text { rating scale given by } \\
\text { immediate superior }\end{array}$ & Discrete \\
\hline $\begin{array}{c}\text { Cooperative ability } \\
\text { 1-10 rating scale given by } \\
\text { immediate superior }\end{array}$ & Discrete \\
\hline Work stress tolerance & $\begin{array}{c}1-10 \text { rating scale given by } \\
\text { immediate superior }\end{array}$ & Discrete \\
\hline $\begin{array}{c}\text { The probability of } \\
\text { staying in firm } \mathrm{X}\end{array}$ & $0=$ Stay; $1=$ Leave & Discrete \\
\hline
\end{tabular}

80 samples from a twenty-year period were used to train the neural network used by equation (2.1) to (2.3). After 1,000 training cycles of the constructed BP neural network, a forecasting accuracy of $84.31 \%$ was obtained with an average error rate of 0.16 .
Table 2. Weight value of each factor as assigned by BP neural network

\begin{tabular}{|c|c|}
\hline Indicator & Weight values \\
\hline Previous working experience & 0.0068 \\
\hline Family status & 0.0010 \\
\hline Professional proficiency & 0.0215 \\
\hline Cooperative ability & 0.0349 \\
\hline Work stress tolerance & 0.0354 \\
\hline
\end{tabular}

In terms of factors affecting the MAs' willingness to continue working in firm Y, Table 2 shows that work stress tolerance was the most significant indicator utilized by equation (2.4), followed by cooperative ability. The least important factor was family status. These results indicate that working attitude is far more important than personal characteristics.

Subsequently, the BP neural network prediction model was applied in the inference case of the 20 current MAs. It ascertained that four of the MAs were likely to resign from their positions following the probationary period. Table 3 presents the significance of each indicator in terms of its power to predict the retention of MAs. Interestingly, work stress tolerance and cooperative ability were below average. In other words, the phenomenon can be seen that the problem is occurred in the MA her/himself working attitude or recognition.

In order to examine the accuracy of the BP prediction model, in the week before the end of the probationary period firm $\mathrm{Y}$ issued an anonymous questionnaire to evaluate the current MAs' intention of remaining in their positions. The results were in accordance with the predictions presented in Table 3: \#4, \#16, and \#20 intended to leave firm Y and while \#17 expressed the intention to stay, his performance was considered to be 'unfit for the position' by the management of firm Y. This example clearly indicates the high level of accuracy of the proposed BP network prediction model.

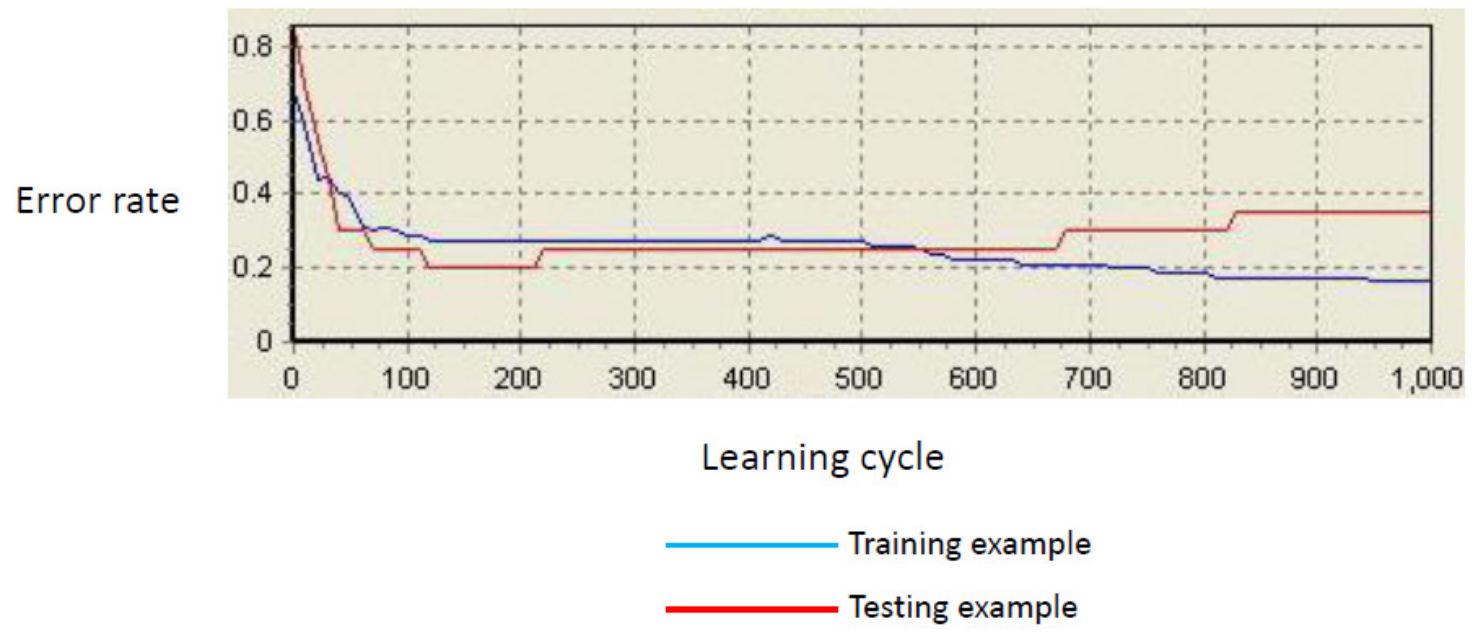

Figure 2. Error rate convergence of BP network 
Table 3. Indicators showing probability of retention of current MAs

\begin{tabular}{|c|c|c|c|c|c|c|}
\hline MA\# & $\begin{array}{c}\text { Previous } \\
\text { experience }\end{array}$ & Family status & $\begin{array}{l}\text { Professional } \\
\text { proficiency }\end{array}$ & $\begin{array}{c}\text { Cooperative } \\
\text { ability }\end{array}$ & $\begin{array}{l}\text { Work stress } \\
\text { tolerance }\end{array}$ & $\begin{array}{c}\text { The probability of staying in } \\
\text { firm Y }\end{array}$ \\
\hline 1 & 0 & 0 & 3 & 5 & 4 & 0 \\
\hline 2 & 0 & 0 & 2 & 6 & 2 & 0 \\
\hline 3 & 1 & 0 & 4 & 5 & 8 & 0 \\
\hline 4 & 1 & 0 & 8 & 3 & 2 & 1 \\
\hline 5 & 2 & 1 & 4 & 1 & 8 & 0 \\
\hline 6 & 3 & 2 & 2 & 3 & 4 & 0 \\
\hline 7 & 0 & 1 & 1 & 5 & 2 & 0 \\
\hline 8 & 0 & 0 & 1 & 3 & 6 & 0 \\
\hline 9 & 0 & 0 & 1 & 2 & 5 & 0 \\
\hline 10 & 1 & 0 & 6 & 5 & 4 & 0 \\
\hline 11 & 0 & 0 & 4 & 4 & 6 & 0 \\
\hline 12 & 0 & 1 & 4 & 6 & 8 & 0 \\
\hline 13 & 2 & 0 & 5 & 5 & 7 & 0 \\
\hline 14 & 4 & 2 & 5 & 2 & 2 & 0 \\
\hline 15 & 0 & 0 & 5 & 6 & 6 & 0 \\
\hline 16 & 1 & 0 & 4 & 3 & 4 & 1 \\
\hline 17 & 1 & 0 & 1 & 4 & 5 & 1 \\
\hline 18 & 2 & 1 & 6 & 2 & 7 & 0 \\
\hline 19 & 0 & 1 & 5 & 6 & 5 & 0 \\
\hline 20 & 0 & 0 & 2 & 4 & 4 & 1 \\
\hline
\end{tabular}

\section{Discussion and Conclusion}

Based on our results, this study makes the following recommendations:

1. Effective long-term employee-employer relations are based on mutual compatibility, especially for higher level positions. Integrating the corporate reserve cadre into the organizational culture is obviously an important issue because of the 'talent shortage phenomenon' is widely common in SMEs. It is also important for firms to work to develop as a transparent, inclusive, and collaborative organization in order to attract quality talent.

2. Despite many advancements in recruitment procedures such as multidimensional career psychology tests, professional skill tests, and face-to-face interviews, many blind spots remain. The probationary period plays the role of gatekeeper, but involves high costs in terms of training time and financial resources. Enterprises, particularly SMEs, need to implement HR validation mechanisms in order to prevent the outflow of funds, knowledge, and time on staff education and training. This study provides a practical tool with strong predictive power in the form of the BP neural network for examining the suitability of MAs.

3. Our results show that working attitude and interpersonal skills were better indicators of MA retention than professional ability. It seems that effective interpersonal relationships are the key success factor for the training of new MAs. They allow for a smooth transition to a new corporate culture and facilitate a win-win relationship between employer and employee. In addition to emphasizing the idea of the staff functioning as the 'family' of the firm when training new employees, management must be aware of newcomers who fail to integrate into the internal culture of the firm. Prompt decisions may allow managers to avoid unnecessary losses.

This study only focused on the intentions of MAs during the probationary period. This meant our sample primarily comprised job seekers in entry-level positions who possessed little work experience. Possible directions for future research include targeting recently recruited senior managers. Although examination of trends of these employees during the probationary period might not produce as dramatic results, it is reasonable to assume that the results would present more meaningful implications.

\section{REFERENCES}

[1] Schultz, Therodore. 1961. "Investment in Human Capital." The American Economic Review 51(1): 1-17.

[2] Hurrell, Scott A., and Dora Scholarios. 2014. "The people make the brand: reducing social skills gaps through person-brand fit and human resource management practices." Journal of Service Research 17: 54-67.

[3] Ployhart, Robert E., and Thomas P. Moliterno. 2011. 
"Emergence of the human capital resource: A multilevel model." Academy of Management Review 36(1): 127-150.

[4] Barney, Jay B., David J. Ketchen Jr. and Mike Wright. 2011. "The future of resource-based theory revitalization or decline?" Journal of Management 37(5): 1299-1315.

[5] Barney, Jay. 1991. "Firm resources and sustained competitive advantage", Journal of management 17(1): 99-120.

[6] Fitzsimmons, Stacey R. and Christina L. Stamper. 2014. "How societal culture influences friction in the employeeorganization relationship." Human Resource Management Review 24(1): 80-94.

[7] Bambacas, Mary and T. Carol Kulik. 2013. "Job embeddedness in China: how HR practices impact turnover intentions." The International Journal of Human Resource Management 24,(10): 1933-1952.

[8] Björkman, Ingmar, Mats Ehrnrooth, Kristiina Mäkelä, Adam Smale and Jennie Sumelius. 2013. "Talent or not? Employee reactions to talent identification." Human Resource Management 52(2): 195-214.

[9] Lee, Cynthia, Jun Liu, Denise M. Rousseau, Chun Hui and Zhen Xiong Chen. 2011. "Inducements, contributions, and fulfillment in new employee psychological contracts." Human Resource Management 50(2): 201-226.

[10] Hui, Chun, Lee, Cynthia, and Denise M. Rousseau. 2004. "Psychological contract and organizational citizenship behaviour in China: Investigating generalizability and instrumentality." Journal of Applied Psychology 89(2): 311321.

[11] Wright, Patrick M. and Gary C. McMahan. 2011. "Exploring human capital: putting 'human' back into strategic human resource management." Human Resource Management Journal 21(2): 93-104.

[12] Jantan, Hamidah, Abdul Razak Hamdan, and Zulaiha Ali Othman. 2009. "Knowledge discovery techniques for talent forecasting in human resource application." World Academy of Science, Engineering and Technology 3(2): 620-628.

[13] Huang, Mu-Jung, Yee-Lin Tsou, and Show-Chin Lee. 2006. "Integrating fuzzy data mining and fuzzy artificial neural networks for discovering implicit knowledge." Knowledge-Based Systems 19(6): 396-403.

[14] Chien, Chen-Fu, and Li-Fei Chen. 2008. "Data mining to improve personnel selection and enhance human capital: A case study in high-technology industry." Expert Systems with applications 34(1): 280-290.

[15] Tung, Kuan-Yeh, Huang, Ing-Chung, Chen, Shu-Ling and Shih, Chih-Ting. 2005. "Mining the generation Xer's job attitudes by artificial neural network and decision tree: empirical evidence in Taiwan" Expert Systems and Applications 29(4): 783-794.

[16] Strohmeier, Stefan, and Franca Piazza. 2013. "Domain driven data mining in human resource management: A review of current research." Expert Systems with Applications 40(7): $2410-2420$

[17] Rumelhart, David E., Geoffrey E. Hinton, and Ronald J. Williams. 1985. Learning internal representations by error propagation. No. ICS-8506. California University San Diego La Jolla Institute for Cognitive Science.

[18] Hecht-Nielsen, Robert. 1989. "Theory of the backpropagation neural network." Neural Networks. IJCNN., International Joint Conference on. IEEE, 1989. 